\title{
sciendo
}

DOI 10.2478/sbe-2020-0060

SBE no. 15(3) 2020

\section{CLUSTER ANALYSIS OF REGIONAL RESEARCH AND DEVELOPMENT DISPARITIES IN EUROPE}

\author{
PUIU IONELA-ANDREEA \\ The Bucharest University of Economic Studies, Romania \\ NECULA MARIAN \\ The Bucharest University of Economic Studies, Romania
}

\begin{abstract}
:
The European continent distinguished as an entity with genuinely regionalized economic structures. Considering the existing economic disparities in the European regions were found several reasons for the regional aggregation of research and innovation activities. Our study aims to assess the European region's total factor productivity performance of knowledge production for the period 2009-2018, proposing to identify several clusters in the European countries based on their innovative potential and their total factor productivity. The present research evaluates the performance of regional knowledge production in the European countries by using the Malmquist Index procedure. We expect to assess the efficiency of research and development inputs in knowledge production and the contribution of the total factor productivity to the innovative capacity building. The source of data was the Eurostat database. To estimate the knowledge production achievement in the European countries, we examined the total research and development expenditures and the number of researchers involved in this activity as conventional inputs in determining the Malmquist Index. As output, we considered the number of patents applied at the European Patent Office. We applied cluster analysis to identify potential factors that determine disparities among different levels of development of innovation capacity and to detect similarities within the identified clusters.
\end{abstract}

Key words: Innovation; Factor Productivity; Cluster Analysis; Malmquist Total Factor Productivity Index.

\section{Introduction}

Europe distinguished as a conglomerate of well-defined economic and societal structures, characterized by contrasting political governments that unquestionably influenced the innovative and technological performance of the inquired countries, leading to economic potential and productivity disparities in the regions. Over the last decades, was observed a local concentration of economic activities due to the presence of local networks and knowledge clusters that determined a faster development of those distinct regions compared with the rest of the continent. Moreover, the economic inequalities 
among the European regions lead to regional agglomeration of differentiated activities in the European territories.

An existing study (Navarro et al., 2009) identified eight regions according to their innovative capability. Those regions vary from highly advanced regions to peripheral areas.

Most of the Central and East European countries were part of the clusters with the lowest level of innovative potential, which display a delay in their growth process. After the economic integration of these former communist countries, the break within the regions, regarding their degree of development, was reduced, but the discrepancies still exist.

The present paper aims to determine the European countries' total factor productivity performance of knowledge production for the 2009-2018 period, using the Malmquist Total Factor Productivity Index procedure. We expect to find valuable pieces of information' regarding the efficiency of the research and development expenditures in knowledge production and to identify if there exists an innovative capacity building. It is expecting that positive values of the total factor productivity to contribute to the growth of the innovative capacity. Secondly, the actual research employed a hierarchical cluster analysis method to group countries based on their Malmquist Index to observe existing differences from $2009^{\text {th }}$ to $2018^{\text {th }}$.

The paper is organized as follows. The first section realizes a brief review of the existing studies in the domain. The second section describes the research methodology that we applied to the gathered data, while the third section presents in detail our findings. The last part of the paper summarizes the obtained results, exposes the practical implications, and briefly describes the limitations and future intentions of our research.

\section{Literature review}

The European landmass distinguishes by the heterogeneity of economic, political, and social transformations that encompass together countries with different levels of development. At the beginning of the ' $90^{\text {s }}$, the central and east European countries began to implement the so-called post-socialist transition. The intention was to restructure the economies; to open their markets to integrate into the European market and world production chain. Before the $2000^{\text {s }}$, those regions crossed a series of administrative reforms that proposed to privatize the existing economic enterprises and the local governmental institutions.

Research carried by Heidenreich (1998) described the European continent as a "regionalized economic structure" (Heidenreich, 1998). Territories that distinguished by economic prosperity and low rates of unemployment were those in the closeness of large urban centers that were also identified by a regional agglomeration of companies.

The same research (Heidenreich, 1998) divided the European territory into eight economic regions: metropolitan service regions, semi-peripheral service regions, poor service regions, industrial core regions, industrial semi-periphery, industrial periphery, and collapsed industrial regions.

The metropolitan service region was characterized by the highest rate of labor force participation, the lowest level of unemployment, and the highest level of the GDP per capita, from all the analyzed regions. On the other side, the metropolitan region 
distinguished by low levels of labor force participation rate, the highest unemployment rate, and the lowest levels of the GDP per capita.

With the integration in the European Union, the east and central European countries unified with more developed countries, reducing the economic, social, and regional inequalities among the European regions. However, the regional innovation scoreboard classifies the east and central regions as "lagging" compared to the European Union average (European Comission, 2017). To minimize this exiting gap, those regions should increase the research and development capabilities and innovative capacity.

In this regard, we considered that the performance of regional knowledge production is related to the changes in the total factor productivity.

The knowledge production concept presented as a functional relationship among the research and development as an input factor, and the number of applied patents, as output factor, appeared firstly in 1979 in the Griliches work (1979).

Total factor productivity identifies as a source of long-run economic growth being described in the context of the "knowledge economy" framework (Romer, 1986; Comin, 2017). The total factor productivity measures fluctuations in returns to factors used in production in a specific industry. Also, the total factor productivity does not necessarily realize a distinction in the regions based on their knowledge production capabilities but on their efficiency in using the available resources.

Some studies evaluated the performance of the European regions based on the regional innovative capacity. Several studies (Buesa et al., 2006; Vogel, 2015) considered regions as units of analysis in investigating knowledge production in the territory. This approach is sustained by the fact that performant companies are concentrated in specific regions, where also coexists a network of research institutions, universities, or other regional determinants that influence the prosperity of that particular areas and also the productivity of knowledge creation.

The specialized literature also signalled the existence of disparities due to the economic capacity and the research and development investments. It was revealed that the $2008^{\text {th }}$ economic crisis affected the research and development investments from the emerging European regions (Archibugi and Filippetti, 2011).

Another aspect that generates local disparities is knowledge production capacity. There was revealed that eastern European countries are described by lower levels of innovation outputs relative to the human capital that is employed in the research and development activity. Low levels of productivity in knowledge output conduct to low levels of financial absorptive capacity in these countries.

Considering the existing literature on knowledge production performance in the European regions, we would like to realise a contribution to the existing theory regarding the European country's productivity performance.

One of the most recognized criteria to measure the performance of units of analysis, even if we talk about regions, countries, or firms, is based on the comparisons of their levels of efficiency and productivity. Even if static investigations provide relative understanding, the analysis of total factor productivity, in longer periods of time, provides valuable information's about the units of analysis performances on topics like technological advantage, competitive power, knowledge production, decision making, and policymaking. 


\section{Research methodology}

A common method of measuring the production performance of countries is based on comparing productivities and efficiencies. To determine the total factor productivity performance in the European countries, we employed the Malmquist Index procedure. This index is calculated using as input factors the number of employees in the research and development activity and the research and development expenditures and as output variable the number of patents applied at the European Patent Office (EPO).

When there are compared units in longer periods of time, the analysis of changes in total factor productivity and its components are used as a benchmark. The Malmquist Total Factor Productivity Index is calculated using the following equation:

$$
\begin{aligned}
& \mathrm{m}_{0}\left(\mathrm{i}_{\mathbf{t}+1}, \mathrm{o}_{\mathbf{t + 1}}, \mathrm{i}_{\mathbf{t}}, \mathrm{o}_{\mathbf{t}}\right)=\left[\frac{\mathrm{d}_{0}^{\mathrm{t}}\left(\mathrm{i}_{\mathrm{t}+1}, \mathrm{o}_{\mathrm{t}+1}\right)}{\mathrm{d}_{0}^{\mathrm{t}}\left(\mathrm{i}_{\mathrm{t}, 0_{\mathrm{t}}}\right)} \cdot \frac{\mathrm{d}_{0}^{\mathrm{t}+1}\left(\mathrm{i}_{\mathrm{t}+1}, \mathrm{o}_{\mathrm{t}+1}\right)}{\mathrm{d}_{0}^{\mathrm{t}+1}\left(\mathrm{i}_{\mathrm{t}, 0_{\mathrm{t}}}\right)}\right]^{1 / 2} \text {, where } \\
& i=\text { inputs (one or more) } \\
& o=\text { outputs (one or more) } \\
& \frac{d_{0}^{t}\left(i_{t+1}, o_{t+1}\right)}{d^{t}\left(i_{t}\right)} \\
& d_{o}^{t}\left(i_{t, o_{t}}\right)=\text { efficiency change, from period } t \text { to } t+1 \\
& \frac{d_{0}^{t+1}\left(i_{t+1}, o_{t+1}\right)}{d_{0}^{t+1}\left(i_{\left.t, o_{t}\right)}\right)} \\
& d_{o}^{t+1}\left(i_{t_{,} o_{t}}\right)=\text { technological change, from period } t \text { to } t+1 \\
& \text { Equation (1) }
\end{aligned}
$$

The total factor productivity index is calculated by determining the distance functions $\left(\boldsymbol{d}_{\boldsymbol{o}}^{\boldsymbol{t}}\right.$ and $\boldsymbol{d}_{\mathbf{0}}^{\boldsymbol{t + 1}}$ ) for two successive periods. We calculated the Malmquist Index using productivity (Dakpo et al., 2018) package from the Comprehensive R Archive Network (CRAN). Secondly, we applied a hierarchical cluster procedure using the average method, the distance between clusters being the average of the distance among points from the same cluster and points in another cluster.

The source of data used in this study is the Eurostat database (Eurostat, 2020). We collected data for 34 European countries from $2009^{\text {th }}$ to $2018^{\text {th }}$. As input variables, we choose the number of employees in the research and development activity and the value of expenditures from the research and development sector. As output variables, we considered the number of patents applied at the European Patent Office (EPO). Table 1 presents a description and summary statistics for the variables.

Table 1. Variable definitions and summary statistics

\begin{tabular}{c|ccccc}
\multicolumn{1}{c}{ Variable } & Definition & Mean & SD & Max. & Min. \\
\hline Human capital & R\&D personnel and research; all sectors; & 150.1 & 97.03 & 319 & 1 \\
& fulltime equivalent & & & \\
R\&D Expenditure & All sectors; euro per inhabitant & 152.6 & 97.68 & 322 & 1 \\
Patent Application & Application to EPO; per million inhabitants & 2196 & 4783.22 & 27328 & 6
\end{tabular}

Source: Author's calculation

Some countries registered missing values for the chosen period, and we used as an imputation method the mean value of the available scores for that specific country. All 
the statistical procedures that we performed were realized using the $\mathrm{R}$ statistical and programming software (R Core Team, 2020).

\section{Findings}

The Malmquist index was estimated for each year for the analysed time, but we choose to summarize only the results for the beginning period, 2010, and for the final period, namely, 2018. We noticed that there are meaningful variations in the case of Austria and the Czech Republic, where the index recorded a striking decrease from 2010 to 2018. On the other side, Poland and Romania registered a significant increase of the Malmquist Index from 2010 to 2018. We booked the Malmquist index scores in the following table (Table 2).

Table 2. Malmquist Index 2010; 2018

\begin{tabular}{|c|c|c|c|}
\hline Country & $\begin{array}{l}\text { Country } \\
\text { Code }\end{array}$ & $\begin{array}{c}\text { Malmquist Index } \\
2010\end{array}$ & $\begin{array}{c}\text { Malmquist Index } \\
2018\end{array}$ \\
\hline \multirow{3}{*}{$\begin{array}{c}\text { Austria } \\
\text { Belgium } \\
\text { Bosnia Herzegovina }\end{array}$} & AT & 4.2409 & 0.9720 \\
\hline & BE & 1.2475 & 1.0248 \\
\hline & BA & 0.0000 & 0.0000 \\
\hline \multirow{3}{*}{$\begin{array}{c}\text { Bulgaria } \\
\text { Czech Republic } \\
\text { Cyprus }\end{array}$} & BG & 0.6365 & 0.8742 \\
\hline & $\mathrm{CZ}$ & 6.3309 & 0.2555 \\
\hline & $\mathrm{CY}$ & 1.1345 & 0.8406 \\
\hline Croatia & HR & 0.8626 & 1.2656 \\
\hline \multirow{2}{*}{$\begin{array}{c}\text { Denmark } \\
\text { Switzerland }\end{array}$} & DK & 1.2565 & 1.1196 \\
\hline & $\mathrm{CH}$ & 1.1660 & 0.4269 \\
\hline Estonia & EE & 0.1362 & 0.8514 \\
\hline Finland & $\mathrm{FI}$ & 1.1454 & 0.9421 \\
\hline France & FR & 1.0480 & 0.2684 \\
\hline Germany & DE & 1.0607 & 1.0125 \\
\hline Greece & GR & 0.8722 & 1.0992 \\
\hline Ireland & $\mathrm{IE}$ & 1.0232 & 1.3404 \\
\hline \multirow{2}{*}{$\begin{array}{c}\text { Iceland } \\
\text { Italy }\end{array}$} & IS & 1.2506 & 0.5893 \\
\hline & IT & 1.0372 & 0.9452 \\
\hline Latvia & LV & 0.6436 & 0.8601 \\
\hline Lithuania & LT & 0.6711 & 1.4928 \\
\hline \multirow{2}{*}{$\begin{array}{c}\text { Luxembourg } \\
\text { Malta }\end{array}$} & LU & 1.0942 & 0.8100 \\
\hline & MT & 0.4201 & 0.7449 \\
\hline \multirow{2}{*}{$\begin{array}{c}\text { Norway } \\
\text { Netherlands }\end{array}$} & NO & 0.2321 & 1.1397 \\
\hline & NL & 0.7853 & 0.8884 \\
\hline Poland & PL & 1.0468 & 4.5079 \\
\hline Portugal & PT & 0.7220 & 1.3953 \\
\hline \multirow{2}{*}{$\begin{array}{c}\text { Romania } \\
\text { Russia }\end{array}$} & RO & 0.9493 & 5.7136 \\
\hline & RU & 1.1069 & 1.1032 \\
\hline Slovakia & SK & 0.8430 & 1.2168 \\
\hline Slovenia & SI & 1.0919 & 0.9571 \\
\hline Spain & ES & 1.1392 & 1.0162 \\
\hline Sweden & SE & 1.1400 & 1.0360 \\
\hline \multirow{2}{*}{$\begin{array}{c}\text { Turkey } \\
\text { United Kingdom }\end{array}$} & TR & 1.3821 & 0.5654 \\
\hline & GB & 1.1155 & 1.0373 \\
\hline Hungary & $\mathrm{HU}$ & 0.9020 & 0.9729 \\
\hline
\end{tabular}

Source: Author's calculation 
To visualize better the existing differences in the fluctuations in the Malmquist Index, we mapped the results registered in the European countries. Those maps were realized with the rnaturalearth package (South, 2017).

It could be observed that Norway and Estonia registered the lowest scores in 2010th, while Austria and the Czech Republic are on the opposite side, recording the highest scores. In $2018^{\text {th }}$, we observed that the lowest scores were in France and the Czech Republic. Meaningful signs of progress were in Poland and Romania.

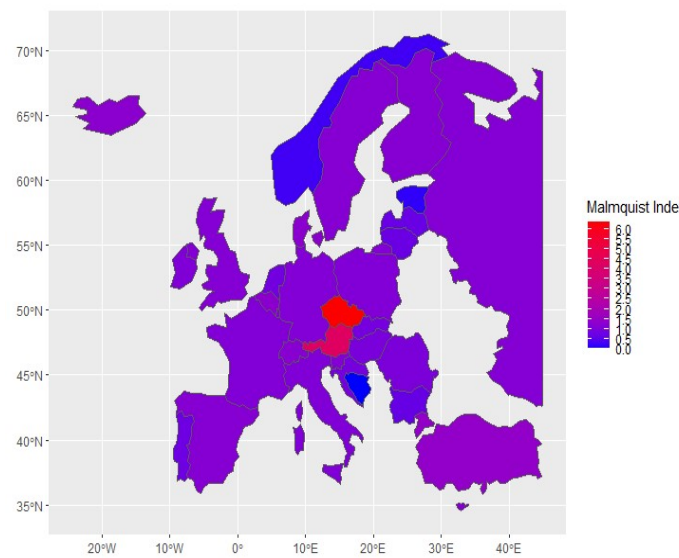

Fig 1. Malmquist Index 2010

Source: Author's calculation

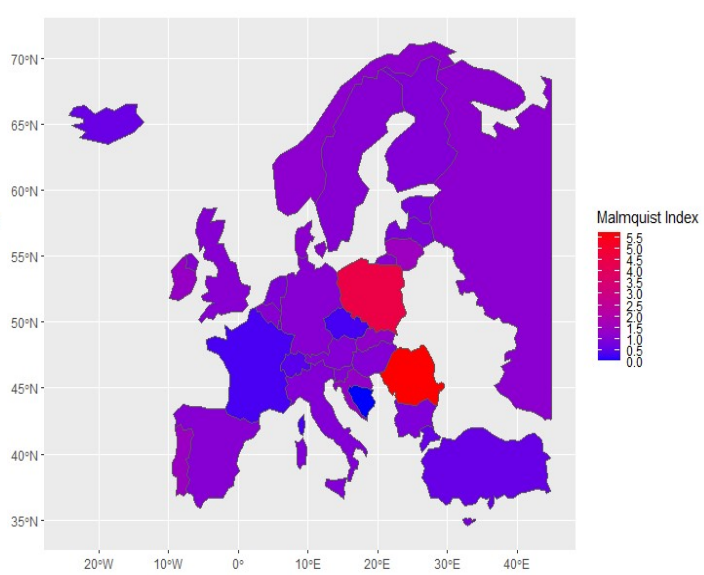

Fig 2. Malmquist Index 2018

Source: Author's calculation

In the second part, we applied a hierarchical cluster analysis using as clustering method the average, and as distance, the Euclidian distance. The dendrogram revealed the existence of five clusters in both periods of time. We will analyse each cluster briefly in the following.

In $2010^{\text {th }}$, there is highlighted a big cluster that comprises countries like Ireland, Germany, Italy, France, Poland, Luxembourg, Slovenia, Russia, United Kingdom, Switzerland, Finland, Cyprus, Spain, Turkey, Denmark, Belgium, Iceland (Fig. 3). It is observable fact that most of the countries from this cluster are from the western part of Europe, region recognized as the most developed and rich region of Europe. Interesting is the appearance of Poland and Turkey in this cluster.

The countries from western Europe are characterized by high levels of research and development expenditures, low levels of unemployment, and high levels of GDP per capita. As previously stated, it is surprising to find Poland in this cluster, a former communist country. We consider that the adherence to the European Union in 2004 ${ }^{\text {th }}$ endowed Poland with the economic power and prosperity to be cohesive with more developed countries.

The second cluster comprises countries like Romania, Hungary, Slovakia, Croatia, Greece, Lithuania, Bulgaria, Latvia, Portugal, and the Netherlands. The second cluster is formed preponderantly by central and eastern European countries that undergo significant transformations since the fall of the planned economy. 
The third cluster is composed of Malta, Bosnia Herzegovina, Estonia, and Norway. Those countries are characterized by low values of the Malmquist Index and by small numbers of patents applied at the European Patent Office in the analysed period (EPO).

The fourth and fifth clusters are composed of independent countries, namely Austria and the Czech Republic, that registered extremely high values of the Malmquist Index.

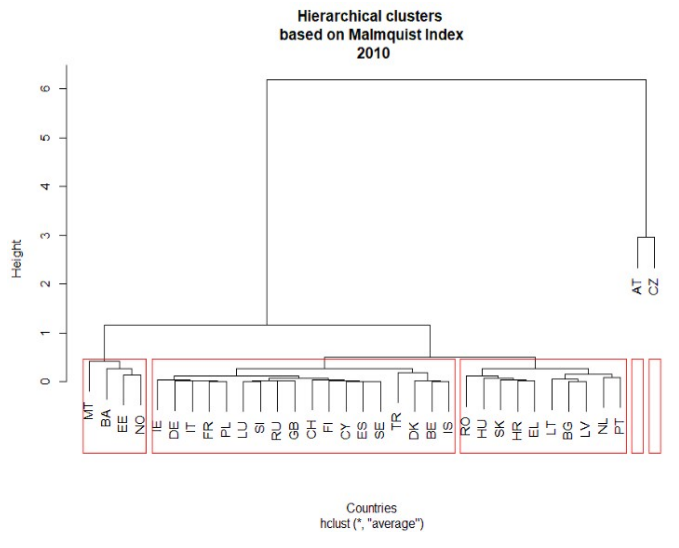

Fig 3. Hierarchical cluster - Malmquist 2010 Source: Author's calculation

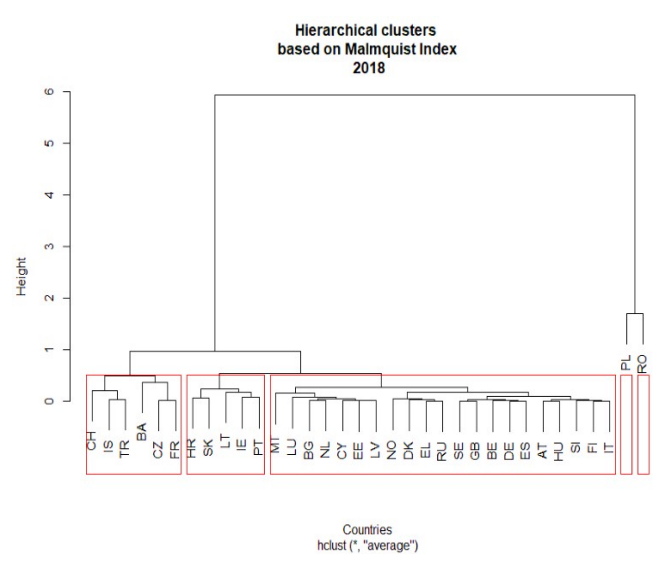

Fig 4. Hierarchical cluster - Malmquist 2018 Source: Author's calculation

In $2018^{\text {th }}$, the componence of the clusters radically changed. The largest cluster comprises countries like Malta, Luxembourg, Bulgaria, Netherlands, Cyprus, Latvia, Norway, Denmark, Greece, Russia, Sweden, United Kingdom, Belgium, Germany, Spain, Austria, Hungary, Slovenia, Finland, Italy. Countries from this cluster registered scores of the Malmquist Index in the interval 0.7449 (Malta) and 1.1196 (Denmark). We would characterise this cluster as being the integration of the former communist countries from central and eastern Europe with the most developed countries of the European Union. In this respect, it is revealed the fact that the European Union Regional Policy to eradicate the gap inside the European Union regarding the economic, social, and regional inequalities was somehow accomplished. This cluster comprises two countries that are not part of the European Union, Norway, and Russia.

The second cluster comprises countries like Switzerland, Iceland, Turkey, Bosnia Herzegovina, Estonia, and Norway. Those countries are characterised by a decrease in their Malmquist index from $2010^{\text {th }}$ to $2018^{\text {th }}$.

The third cluster is composed of Croatia, Slovakia, Lithuania, Ireland, and Portugal. Those countries are characterised by doubling the value of the index from $2010^{\text {th }}$ to $2018^{\text {th }}$.

Again, the fourth and fifth clusters were composed of independent countries, this time by Poland and Romania. Those two countries are former communist countries that were characterised by low levels of investment in research and development. Poland adhered to the European Union in $2004^{\text {th }}$ and Romania in $2007^{\text {th }}$, creating the economic and social legal framework to increase their investments in research and development. From $2010^{\text {th }}$ to $2018^{\text {th }}$, Poland increases fourth times its Malmquist Index, while Romania increased fifth times its index. 
We graphically represent those clusters in two distinct maps, for the beginning and the end of the analysed period (Fig. 5 and Fig. 6).

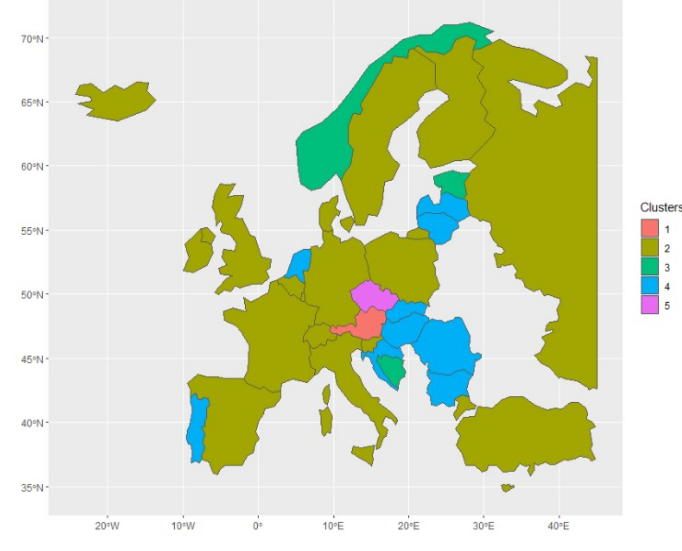

Fig 5. Cluster Countries - Malmquist Index 2010 Source: Author's calculation

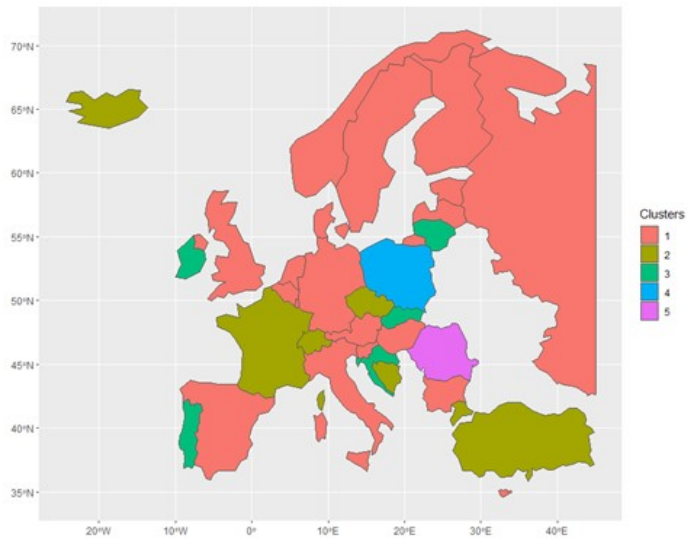

Fig 6. Cluster Countries - Malmquist Index 2018 Source: Author's calculation

\section{Discussions and implications}

The present research proposed to determine the European countries' total factor productivity performance of knowledge production for the 2009-2018 period, using the Malmquist Total Factor Productivity Index procedure. Also, to group countries based on their Malmquist Index score using a hierarchical clustering procedure.

In the case of the Malmquist Index, we observed important variations in the case of Austria and the Czech Republic, where the index score recorded a striking decrease from 2010 to 2018. Poland and Romania registered a significant increase in the Malmquist Index from 2010 to 2018.

The hierarchical cluster procedure revealed the emergence of five regions in Europe, contradicting previous research that identifies the presence of eight regions in the European territory. An important cluster that emerged in $2010^{\text {th }}$ was the one that comprised, mainly, western countries, recognised as the most developed, prosper, and rich regions from the continent. Those countries invest considerable amounts in technologies and innovations, dispose of the higher number of employees in research activity and detain important numbers of the patents applied at the European Patent Office.

The second important cluster that we identified in $2010^{\text {th }}$ is the group of former communist countries. Those regions have gone through a period of administrative reforms to adhere to a market economy while focusing on attracting foreign investment for the development of emerging technologies and industries.

Special attention was paid to Austria and the Czech Republic. Those countries were highlighted as independent clusters because of the registration of the highest values of the Malmquist Index in $2010^{\text {th }}$ and the highest number of patents applied at the European Patent Office. 
Regarding the $2018^{\text {th }}$ year, we observed important trajectories within clusters. The first essential difference was the integration of former communist countries with the western regions, the discrepancies regarding their research and development investments, technological progress, and knowledge capacity were minimised. Even if those differences still exist, they are not so prominent. This time, special attention was paid to Poland and Romania, which formed independent clusters. Those two countries registered amazing increases in the Malmquist index from the beginning to the end of the analysed period.

Practical implications of the actual research derive from the fact that by calculating the Malmquist Index is possible to observe variations in the productivity of the research and development expenditures and the human factor in the European region. It was observed notable progress in the central and east European countries regarding their innovative capacity building. On the other side, the breakdown of some distinct regions in accomplishing the efficiency gains could be interpreted as a collapse in the administration of the research and development resources. A restructuring of the developing strategies and a more targeted purpose should be held in those regions.

The actual study proposes to constitute a comparison base for future studies regarding the evolution of regional productivity and efficiency change in European countries.

\section{Limitations and future research}

Even if our research contributes to relevant information regarding the efficiency of the research and development expenditures in knowledge production and distinguishes inherent innovative capacity building in the analysed countries, some limitations should be considered when inferring the results of the present research.

Our first limitation arises from data-limited accessibility. In the Eurostat database, the variables that we have used in the present research were only accessible for the period 2008-2018. Because multiple values were missing for the $2008^{\text {th }}$, we reduced the analysis to 2009-2018. However, various countries present missing observations of the investigated variables.

In this context, raised the second limitation of the study, the imputation method. We used as imputation method of the missing values the mean. We will not be sure if this method is the most appropriate one if we do not perform multiple imputation methods and compare the performance of each one taking separately. That is something that we are considering for future research.

The second limitation arises from the clustering algorithm that we employed and the distance among clusters, namely the Euclidian distance. Again, there will be of interest to perform various techniques of cluster analysis and different distances to observe if there are provided diverse estimations of clusters and heterogeneous elements that would lead to inconsistent interpretations.

As future research, we intend to extend our analysis to a longer period, if data will be available, and to a wider area. Also, we aim to decompose the Malmquist Index into its two main categories of factor productivity, efficiency change, and technological change. 


\section{References}

Archibugi, D., Filippetti, A., (2011), Is the economic crisis impairing convergence in innovation performance across Europe? JCMS: Journal of Common Market Studies, Vol. 49, no. 6, pp. 1153-1182.

Buesa, M., Heijs, J., Pellitero, M. M., Baumert, T., (2006), Regional systems of innovation and the knowledge production function: the Spanish case. Technovation, Vol. 26, no. 4, pp. 463-472.

Comin, D., (2017), Total factor productivity. The New Palgrave Dictionary of Economics. Springer, pp. 1-4.

Dakpo K.H., Desjeux Y., Latruffe L., (2018), productivity: Indices of Productivity and Profitability Using Data Envelopment Analysis (DEA). Available at: https://CRAN.R-project.org/package=productivity/.

European Commission: Regional Innovation Scoreboard 2017. EC Report (2017), Eurostat Database. Available at: https://ec.europa.eu/eurostat/data/database?node code=hlth (2020), last accessed 2020/11/01.

Griliches, Z., (1979), Issues in Assessing the Contribution of R\&D to Productivity Growth. The Bell Journal of Economics, Vol. 10, no. 1, pp.92-116.

Heidenreich, M., (1998), The changing system of European cities and regions. European Planning Studies, Vol. 6, no. 3, pp. 315-332.

Navarro, M., Gibaja, J. J., Bilbao-Osorio, B., Aguado, R., (2009), Patterns of innovation in EU-25 regions: a typology and policy recommendations. Environment and Planning C: Government and Policy, Vol. 27, no. 5, pp. 815-840.

R Core Team., (2020), R, A language and environment for statistical computing. R Foundation for Statistical Computing, Vienna, Austria. Available at: https://www.Rproject.org/.

Romer, P. M., (1986), Increasing returns and long-run growth. Journal of Political

Economy, Vol. 94, no. 5, pp. 1002-1037.

South, A., (2017). rnaturalearth: World Map Data from Natural Earth. https://CRAN.R-project.org/package=rnaturalearth.

Vogel, J., (2015), The Two Faces of R\&D and Human Capital: Evidence from Western European Regions. Papers in Regional Science, Vol. 94, no. 3, pp. 525-551. 